\title{
Reassessment of English-only approach in EFL context in view of young learners' attitudes, language proficiency, and vocabulary knowledge
}

Jang Ho Lee

\begin{abstract}
A set of young Korean EFL learners $(n=208)$ participated in a multi-instrument study of the relationship between English proficiency and several learner variables. Participants were given 1) a questionnaire exploring their attitudes towards an English-only teaching approach in EFL classrooms and perceptions of teachers' English use, 2) measures of proficiency in their mother tongue and English, and 3) a test of vocabulary knowledge. The results of the regression analysis show that Korean proficiency, vocabulary knowledge, and the amount of English instruction one can understand were strongly predictive of their English proficiency, but their attitudes towards an English-only approach were found to have little relation to English proficiency. The results of the questionnaire analysis further suggest that the young EFL learners involved in the study were not in favor of an English-only teaching approach, which matches previous findings but runs counter to the common assumption that young English learners are less opposed to being exposed to such an approach. The findings here suggest that an English-only approach delivered via one particular English variety is neither a learner-favored one nor a cutting-edge teaching method. Instead, they support the recent movement towards bilingualism.
\end{abstract}

Keywords: English-only approach, Learners' attitudes, L2 vocabulary, L2 proficiency, English as a foreign language

\section{Introduction}

In the Republic of Korea, English fever has spread across the whole nation. The ever-growing power of English has built a strong belief in Korean society that being competent in English is directly connected to success on every level. Meanwhile, the juggernaut of English fever has coincided with modern target language (TL) teaching methodologies in which the maximization of TL input for a better learning outcome is given as a pedagogical maxim (Turnbull and Arnett 2002). The attempt to increase the amount of the TL as much as possible in classrooms has been criticized by Macaro (2009), who argues that such a claim does not have much theoretical or empirical support to date. A considerable number of English as a foreign language (EFL) teaching practitioners, program administrators and parents of EFL learners, however, have taken this pedagogical maxim at face value, and the English-only (EO) teaching approach has gained popularity in English classrooms.

Correspondence: jangho330@gmail.com

Department of English, Korea Military Academy, Seoul, South Korea
A strong preference for the EO teaching approach in Korea is most prominent for parents of young learners. Reportedly, these parents send their children to English speaking countries, hoping that EO environments therein will accelerate their children's English learning (see Bamgbose 2006 for a similar point). A policy of "Teaching English in English (TEE)" proposed by the Korean Ministry of Education (2000) seems to meet these parents' expectations for a higher quality of English education as well as the general trend of English teaching methodologies across the world. However, despite the growing interest in English education and the government's recommendation, we remain far from understanding what our learners think about this teaching approach, and whether their attitude towards the EO agenda has anything to do with their proficiency. In other words, are learners with a greater preference for the EO teaching approach those with higher English proficiency? This question matters to both teaching practitioners and parents, for if EFL learners do have a great preference for such an approach and if those with higher proficiency have positive attitudes towards the EO method,

\section{Springer}


then we should promote this type of learning environment. However, if they are not in favor of this approach and there is no correlation between proficiency and a positive attitude, then the justification for the EO diet for our learners may need to be reconsidered.

The present study addresses a recent call by Bolton et al. (2011) for more research on seeking a "suitable teaching model" in Asian contexts (p. 474), in view of the global change regarding bilingualism and English as an international language. It makes a new contribution by 1) shedding some light on the relationship between young EFL learners' attitudes towards the EO teaching approach and their English proficiency, with the latter having garnered much attention across the Asian region (Bolton 2008); 2) investigating whether other learner variables such as first language (L1) proficiency, vocabulary knowledge, and the degree of their self-reported understanding of teachers' English could account for these learners' English proficiency. These variables have been somewhat overlooked in the discussion of English teaching, though they have been of considerable interest in second language acquisition theories and they might indeed play a significant role in relation to the EO approach and English proficiency. To this end, the study looked at sixth grade EFL students in a public elementary school in Incheon, the third largest city in South Korea, administering several research instruments measuring the aforementioned variables.

\section{Background of study}

English teaching policy in South Korea and assumptions behind the English-only approach

As mentioned in Introduction, the issue of teachers' language use in English education in Korea has focused on the notion of TEE, which "pertains to the use of English between teachers and students during English language class activities" (Seoul Metropolitan Office of Education 2010, p. 10). Concerning the advancement of TEE protocols, Choi et al. (2000) from the Korea Institute of Curriculum and Evaluation proposed three models of English teaching in terms of teachers' language use in teaching different language skills:

Model 1 Listening, Speaking, Reading, Writing, Cultural Aspects of English $\rightarrow$ all through English-only Instruction

Model 2 Listening, Speaking $\rightarrow$ through English-only Instruction

Reading, Writing, Cultural Aspects of English $\rightarrow 80 \%$ Use of English

Model 3 Listening, Speaking $\rightarrow$ through English-only Instruction

Reading, Writing, Cultural Aspects of English $\rightarrow 60 \%$ Use of English

(Adapted from Choi et al. 2000)
Among these three options, Choi et al. (2000) argued that Model 2, which promotes English-only in teaching speaking and listening skills, and enables teachers to use about $80 \%$ use of English in teaching other skills, may be the most realistic and desirable model in the context of English education in Korea. This model, while encouraging a higher amount of English use than Model 3, permits some degree of teachers' first language (L1) use for pedagogical purposes, unlike Model 1 which promotes the exclusivity of English instruction. This view is also shared by Swain et al. (2011) who support the teacher and student use of the L1 "in a planned and judicious manner" (p. 8), in the handbook for English teachers in Hong Kong-another EFL context.

TEE or EO instruction is a highly complex and valueattached concept related to a recent sociolinguistic theory, which is in some regards, controversial itself. For example, Phillipson (1992) introduces five tenets of English Language Teaching (ELT) originating from the Makerere report in 1961, which according to him disclose complex relationships among the English-speaking countries' attempt to retain dominance and control over developing countries, their support for the monolingual approach to ELT and its growth in the modern English teaching profession:

1. English is best taught monolingually.

2. The ideal teacher of English is a native speaker.

3. The earlier English is taught, the better the results.

4. The more English is taught, the better the results.

5. If other languages are used much, standards of English will drop (p. 185).

Although the legitimacy of these tenets has been put into question by several authors (e.g., Cook 1999; Medgyes 1994; Swan 1985) on both pedagogical and political grounds, the EO approach has gained popularity in the field and has brought about several pedagogical consequences. First, educational authorities have argued that TL-only instruction should be used as much as possible, and in Asian English teaching contexts the EO approach (delivered in either UK or US style English by native speakers of those varieties) has become a trendy one. For example, in the EFL context of Hong Kong, the Curriculum Development Council (2004) clearly states that "teachers should teach English through English," and "in all English lessons" if possible (p. 109). As McKay (2002) points out, it is rather difficult to follow this pedagogical recommendation in the EFL environments in which teachers and learners share the same language. On another level, learners' TL competence has been evaluated against monolingual standards (Grosjean 1985). In line with Grosjean, Bolton (2008) raises a similar concern regarding the assessment of the proficiency of Asian English users: 
there are also profound issues about how 'proficiency' might best be measured in Asian contexts, given that many traditional proficiency tests are benchmarked in various ways against inner-circle (UK or US) 'native speaker' patterns of performance, and yet ignore the multilingual proficiency of many Asian users of English (p. 11).

Lastly, it has been implied that the ideal TL teacher is a native speaker of that language (Cook 1999), who presumably makes use of and implements TL-only approach better than their non-native counterparts. This is rather unfortunate, partly because we are far from having any tentative conclusion that the TL-only approach or instruction by native speaker teachers is superior to the bilingual approach to English teaching or that delivered by bilingual teachers (Macaro 2009), and partly because language learners do not generally accept the TL-only approach as an effective and preferable one (see Learners' attitudes towards teachers' language use below). It is also noteworthy that there is an increasing awareness among both the research community and language learners that bilingual teachers have some strengths not shared by their native counterparts (for example, He and Miller 2011; see also several chapters in Llurda 2005) presumably in light of a recent movement of research towards bilingualism and English as an international language (Genesee 2008; Myers-Scotton 2006; Kachru et al. 2006).

Embracing such a trend, the Seoul Metropolitan Office of Education (2010) has recently taken a less assertive position about EO instruction, saying "teachers may switch between English and Korean during class according to the content of the lesson and the students' understanding in order to exercise flexibility" (p. 10), implying that the EO approach may not be the most suitable model of English teaching in their view. Indeed, as Baumgardner (2006) rightly suggests, if we aim to help our English learners to become competent bilinguals, it would be required for English teachers to have knowledge of both TL and L1. This position supporting the integration of learners' L1 may also fit in better with the current status of English as an international language, in which code-switching (between different languages or linguistic varieties) has been found to serve some sociolinguistic functions (Myers-Scotton 1993).

Despite ongoing discussion on this issue, however, young learners' attitudes towards this approach have rarely been studied, let alone its relation to proficiency. The importance of learners' attitudes in language learning will be discussed below, focusing on the TL-only approach.

\section{Learners' attitudes towards teachers' language use}

Each language learner brings to classrooms his or her previous language learning experience, knowledge of language, and perception of various aspects of language learning.
These perceptions progressively mould learners' attitudes towards a certain teaching approach which is embodied and manifests itself through educational policy, curriculum, text materials, teachers' activities and their language use. Learners' attitudes or beliefs about language learning have been claimed to be influential factors in the success of TL learning, with much research in this tradition owing to the work of Horwitz (see Horwitz 1999 for a review). Horwitz developed a questionnaire called The Beliefs About Language Learning Inventory (BALLI) which assesses learners' opinions on various controversial issues related to language learning. A series of studies using the BALLI suggest that learners' beliefs about learning have a critical bearing on their experiences as well as actions they take in classrooms. In line with this proposal, Long (1997) further suggests that instructors "who do not solicit student attitudes often face [problems such as] they ... gain fewer insights into the problems their students are having [and] ... they may continue in certain practices that negatively affect the students' self-esteem, performance" (The Importance of Student Attitudes, para. 3).

Only in recent years have second language (L2) researchers started to pay attention to learners' attitudes towards TL-only instruction or L1 use by their teachers. Although the issue has not garnered much attention from the second or foreign language teaching community in general, the importance of this issue is well summarized by Chavez (2003): "learners' beliefs are central in communicative, learner-centered approaches ... [because learners' views therein] determine how students perceive, interpret, and react to their teachers' actions" (p. 164). In other words, learners' attitudes towards teachers' linguistic repertoire influences their language learning process. We can hypothesize then that learners' positive attitudes towards the EO teaching approach would bear fruit if they were exposed to such an environment. If learners were not in favor of such an approach, being surrounded by English-only approach would possibly have a negative influence.

Research has repeatedly shown that learners' attitudes towards the TL-only approach do not match the ideals of program administrators and teaching practitioners. Rolin-Ianziti and Varshney (2008) found that students enrolled in a French beginner course in which maximizing TL use was promoted preferred their L1 to be used for medium-oriented goals (as in learning vocabulary and grammar). Chavez (2003) observed a tendency among university learners of German to increasingly prefer the TL as they progressed in their TL learning. Still a majority of the participants valued the L1 for communicating with their instructors and understanding various aspects of the TL.

The findings of studies conducted in Asian EFL contexts (Burden 2004; Liu et al. 2004; Yao 2011) strengthen earlier 
ones in that learners as a whole prefer having the L1 as part of their teachers' oral instruction over English-exclusivity. In particular, as far as English vocabulary and grammar are concerned, EFL learners in these studies were greatly in favor of L1 explanations for the sake of comprehensibility. Yao, by implementing the same questionnaire with instructors and learners, further observed that instructors in Chinese EFL classrooms generally share similar beliefs with their learners in terms of teachers' code-switching to the L1, although they disagreed with certain values attached to L1 use (e.g., for discipline purposes).

The findings of the studies on this topic appear to suggest that learners' preference for the L1 in TL learning persists in spite of the strong TL-only (or maximum) approach advocated on an administrative level. While we also see some possibility of a growing preference for more TL input on the part of instructors among learners (Burden 2004; Chavez 2003), it remains unclear as to whether they would still be supportive of TL-only teaching approach and instruction after years of language learning. It is the focus of this study to examine whether young EFL learners share similar beliefs regarding EO instruction with those in previous studies, and whether one could further find any relationship between their attitudes to using the EO approach and proficiency.

\section{The relationship between the $\mathrm{L} 1$ and $\mathrm{TL}$ proficiencies}

In the field of TL learning and bilingual education, the role of the L1 in TL learning has been controversial for decades, with a recurring question among professionals being whether the L1 aids or interrupts the TL learning process. Research has spawned different propositions regarding cross-linguistic influences, each of which we will review briefly below.

A negative view of L1 influence largely comes from studies on Contrastive Analysis (CA). Research in this tradition (e.g., Stockwell et al. 1965; James 1980) draws on the behaviorist theory of learning from psychology and structural linguistics, suggesting that transfer from the L1 is likely to cause interference in TL learning, especially if two languages are considerably different from each other on a structural level. CA research further argues that the main task for TL learners is to get rid of previous L1-based habits, which are deemed sources of interference. The main concern of CA then is to predict those areas of differences between the L1 and TL which would impede TL learning and prevent learners from using their L1 knowledge. The popularity of CA waned, because it was soon found that the proportion of learners' errors resulting from transfer was smaller than claimed by CA.

A more positive view of L1 influence is given by Cummins (1980a, b). In studying the effects of bilingual education and its relationships with learners' language proficiency, Cummins proposes the Interdependence Hypothesis, which makes predictions regarding the development of one's TL proficiency as a function of one's L1 proficiency. In the Interdependence Hypothesis, Cummins distinguishes between two types of language proficiency-basic interpersonal communicative skills (BICS) and cognitive/academic language proficiency (CALP). According to Cummins, BICS refer to everyday conversational skills, including the 'surface' linguistic knowledge required in social interaction. On the other hand, CALP is more related to literacy skills (e.g., writing composition skills) or problem solving skills in cognitively demanding situations (e.g., academic contexts). Cummins suggests that BICS, the surface manifestations of a language, are independent across languages. In other words, each language consists of its own features of syntax, vocabulary, and phonology. On the other hand, CALP - an ability to deal with academic demands-is interdependent and transferable across languages. In his own words, "previous learning of literacy-related functions of language (in the L1) will predict future learning of these functions (in the TL)" (Cummins 1980a, p. 179). Cummins, however, qualifies that learners may need to pass a certain threshold level of proficiency to benefit from the transferring of literacy. Nonetheless, the Interdependence Hypothesis projects a much more positive view of cross-linguistic influence than CA, in particular for groups of learners who have surpassed a certain level of CALP in their L1.

Of two perspectives towards the cross-linguistic influence, the more relevant one to the present study is the Interdependence Hypothesis by Cummins, as general literacy and proficiency are of interest to us. That is, it may be true that while L1 influence could be negative in terms of some specific linguistic elements as CA suggests, L1 and TL proficiencies, particularly in the sense of CALP, may be related (though not causative).

\section{Vocabulary knowledge}

Vocabulary has been regarded as one of the most important areas in TL learning (Laufer 1986; Zimmerman 1997). However, it has also been viewed as an area which is particularly difficult to study and explore, due to its complex nature (Meara 1996; Nation 2001). Researchers like Nation (2001) and Richards (1976) have attempted to define vocabulary knowledge by providing a long list of different parts that make up this knowledge, but soon vocabulary researchers found it to be a rather daunting task to create assessing measures based on such a list. After a certain period of stalemate, Meara (1996) called for a more manageable set of dimensions to define and examine vocabulary knowledge. Having this agenda in mind, some researchers (e.g., Henriksen 1999; Jiang 
2000) have devised their own ways of defining vocabulary knowledge, or "lexical competence," a more preferred term among vocabulary researchers. The studies on this issue seem to have been boosted by Meara's (1996) notes on the importance of vocabulary. In his words "lexical competence is at the heart of communicative competence" (p. 35).

Among vocabulary professionals, vocabulary size or breadth of vocabulary has been proposed to be a strong candidate for constructing lexical competence. Said differently, the more TL words learners know, the higher lexical competence they have. Size of vocabulary has been found to play an essential role in TL reading. As Laufer (1997) puts it, based on previous research, "lexis was found to be the best predictor of success in reading, better than syntax or general reading ability" (p. 31). In addition to reading ability, Meara (1996) suggests that vocabulary size may also be a reliable predictor of other areas, saying that "All other things being equal, learners with big vocabularies are more proficient in a wide range of language skills than learners with small vocabularies" (p. 37). He goes on to argue that we now have an ample amount of evidence suggesting that "vocabulary skills make a significant contribution to almost all aspects of L2 proficiency" (p. 37). The findings of a more recent study by Zareva et al. (2005) lend support to Meara in that some aspects of lexical competence (e.g., breadth and depth of vocabulary knowledge) correlate with the proficiency of L2 learners.

Despite growing interest in the relationship between lexical competence (vocabulary size in particular) and proficiency, there have been few other studies examining this issue, apart from Zareva et al. (2005) mentioned above and previous studies conducted by Meara and his colleagues (Meara and Buxton 1987; Meara and Jones 1988). One of the aims of this study is to examine the extent to which EFL learners' proficiency can be predicted based on lexical competence with a focus on their vocabulary size.

\section{Hypotheses}

The present study examines and extends earlier research findings related to EFL learning, on the basis of which the following hypotheses are formulated:

(1)Learners' L1 proficiency and vocabulary size are reliable predictors of TL proficiency (Cummins 1980a; Meara 1996; Zareva et al. 2005).

(2)Learners' attitudes towards an English-only teaching approach are significantly correlated with their English proficiency.

In addition to these two hypotheses it will also address a third hypothesis:
(3) The amount of teachers' English one can understand (based on learners' self-judgment) is sensitive to their English proficiency.

\section{Methods}

\section{Participants}

The study used a purposive sampling method to draw on participants with the following characteristics: they have been exposed to English-only (EO) instruction, so that they can evaluate the EO teaching approach based on their previous experience (rather than intuition); they have not been living in English-speaking countries (i.e., they are EFL learners); they are not simultaneous bilinguals (i.e., they have not concurrently acquired their L1 and English from birth and onwards); lastly, the participants have learned English in a formal instructional setting (rather than natural settings).

In March 2011, the participants attending a public elementary school in Incheon, South Korea were sampled based on the above criteria. The selected participants were those whose parents agreed to allow their children to participate in the study. The sample was composed of 243 sixth grade learners (12 years old). This number was later reduced to 208, or those who completed all the instruments of the study and who were not removed during data mining (i.e., to check statistical assumptions). Their L1 was Korean and they had learned English as their foreign language for three consecutive years at their school by the time of the study.

\section{Instruments}

The study used four instruments, namely an English proficiency test, vocabulary test, participant questionnaire, and Korean proficiency test. As for the proficiency test, the TOSEL (Test of Skills in the English Language)—an English proficiency test developed for Korean test takers (TOSEL Organization 2011) -was used in the present study for the following reasons. First, the TOSEL is a test originally developed for Korean test takers, and thus takes into account Korean English learners' characteristics better than other English proficiency tests. Second, the TOSEL is divided into six levels according to different age groups of test takers, and thus enables more age-appropriate evaluations. To this ends, the testing instrument used in the doctoral research project (Lee 2010) was adopted, and administered to the participants. This test was of the Basic level, which was originally developed for upper elementary school students (grade 5 and 6). In total, 30 listening test items and 25 reading test items were included in the test. Cronbach's alpha (i.e., reliability) for the test was found to be very high (.909), with the estimates for the subsections being lower than the overall reliability of the test (.843 for the listening section and .840 for the reading section). In 
addition, the test scores were found to be significantly and positively correlated with their school grades in English $(r=.87)$.

Unlike the proficiency test, the vocabulary measure had to be developed from scratch, as there was no specific test available for our target population. In view of the facts that these EFL learners were studying English within the framework of a government-regulated curriculum and that they were relatively at the beginning stages of English learning, the existing vocabulary tests were not suitable for our purposes. The vocabulary test for the present study, thus, was developed with a reference to the list of English vocabulary recommended in the curriculum developed by the Ministry of Education, Science, and Technology (2009). The test was further given vocabulary targeted for a population with slightly higher English proficiency, in order to prevent possible ceiling effects. The vocabulary test was of the receptive type, asking test takers to demonstrate their knowledge of the words by providing a synonym or translation of each word into their L1. In total, 80 lexical items, consisting of nouns (e.g., vegetable, peak), verbs (e.g., understand, forgive), adjectives (e.g., ancient, delicious), and adverbs (e.g., unfortunately, quickly), were included in the test.

The participant questionnaire was designed to investigate young EFL learners' attitudes towards the EO teaching approach as well as to elicit their responses regarding the amount of English they could understand based on their learning experience. A preliminary questionnaire, which is a simplified version of the original questionnaire used in the research project mentioned above, was piloted to 56 sixth grade students attending another public elementary school. The primary purpose of the piloting was to ensure that the questionnaire items were comprehensible to our target population. The preliminary questionnaire was further revised in terms of wording and length. The final questionnaire, including attitudinal statements regarding the EO approach on a Likert scale, was two pages in length, and written in Korean. The questionnaire also included the item asking the amount of teachers' English one can understand (how much can you understand when your teacher speaks English?), on a scale of 0 to $100 \%$.

As for Korean proficiency, the author asked permission from the sampled elementary school for participants' scores on a national scholastic achievement test to be used for research purposes. The school agreed to provide only the total score of each participant on this test, but not their performance on individual test items. It was not possible, thus, to estimate the reliability of the test, though the test can be assumed to have a sufficiently high value on the grounds that it was developed by a group of specialists in this area. The test was more or less similar in format to the English proficiency test described above. The participants' scores on the Korean proficiency test were found to be significantly and positively correlated with their school grades in Korean $(r=.82)$.

\section{Procedure}

In terms of ethical issues, the author first approached the principal and teachers of the sampled school, and discussed the relevant issues (e.g., whether the tests would cause any harm to the participants, how the participants' parents would be informed about the present study). After the consultation, the author sent informed consent forms (opt-out) to the participants' parents, with the help from the teachers therein. The sampled teachers further assured the participants that the testing materials would not affect the participants' school grade in any possible way, and that they had the right to withdraw anytime during the study without any penalty.

The study was carried out over a period of two days, with the English test being administered on the first day and the vocabulary measure and questionnaire being given on the next day. The tests were administered in ordinary classrooms, equipped with individual desks and chairs, whiteboard and a large projection screen. Each classroom was suitable for a class size of 25 to 30 students. The instructions for the tests and questionnaire were given to the participants by reading a script. After explaining the instructions, the proficiency test sheets were distributed and administered for fifty minutes (20 and $30 \mathrm{~min}$ for the listening and reading sections, respectively), on the first day. On the following day, the participants were given instructions regarding the vocabulary measure with examples by the sampled teachers. This test was administered for $25 \mathrm{~min}$. There was a mandatory 10-min break, and after this they proceeded to complete the participant questionnaire, which was administered for $20 \mathrm{~min}$.

\section{Data analysis}

After completing the tests, the researcher and one of the sampled teachers independently scored the answers to the vocabulary test. The value of inter-rater reliability was .92. Discrepancies in scoring were resolved through discussion with another English teacher at the sampled school. The English proficiency test, which was of the multiple choice type, was scored based on the answer sheet provided by the TOSEL organization.

\section{Results}

Table 1 displays the means and standard deviations calculated from the learners' responses to each attitudinal statement related to the EO teaching approach, and the percentages of each response.

It was found that the English-only (EO) or maximum approach drew a rather lukewarm reception from the young EFL learners. This was most clearly visible in 
Table 1 The results of the selected questionnaire items

\begin{tabular}{|c|c|c|c|c|c|c|}
\hline Statement & Mean $^{a}(S D)$ & $\begin{array}{l}\text { S.D } \\
1^{\mathrm{b}}\end{array}$ & 2 & $\begin{array}{l}\% \\
3\end{array}$ & 4 & $\begin{array}{l}\text { S.A } \\
5\end{array}$ \\
\hline 1. Teachers should use only English in English classrooms. & $2.38(1.02)$ & 19.7 & 41.8 & 20.7 & 16.3 & 1.4 \\
\hline $\begin{array}{l}\text { 2. I prefer English-only instruction because it gives } \\
\text { me more opportunity to be exposed to English. }\end{array}$ & $2.87(0.98)$ & 6.3 & 29.8 & 40.9 & 16.3 & 6.7 \\
\hline $\begin{array}{l}\text { 3. The more English students use in the classroom, the } \\
\text { better they will be at communicating in English. }\end{array}$ & $3.14(0.93)$ & 3.4 & 20.2 & 42.3 & 26.9 & 7.2 \\
\hline $\begin{array}{l}\text { 4. I believe that, regardless of how much English students } \\
\text { choose to use, the instructor should use English at all times } \\
\text { in the classroom. }\end{array}$ & $2.39(1.02)$ & 19.2 & 39.9 & 27.4 & 9.6 & 3.8 \\
\hline $\begin{array}{l}\text { 5. When I don't know a word in English, I prefer to have it } \\
\text { explained to me in English, rather than Korean. }\end{array}$ & $3.02(1.01)$ & 8.2 & 18.3 & 44.7 & 21.2 & 7.7 \\
\hline $\begin{array}{l}\text { 6. English-only explanation is necessary because the English } \\
\text { class should provide a maximum amount of English. }\end{array}$ & $2.72(0.95)$ & 9.6 & 29.8 & 43.8 & 12.5 & 4.3 \\
\hline $\begin{array}{l}\text { 7. If understandable, I prefer English-only instructions to Korean } \\
\text { instructions. }\end{array}$ & $3.23(1.14)$ & 8.7 & 13.9 & 39.4 & 21.6 & 16.3 \\
\hline
\end{tabular}

Note:

${ }^{a}$ The mean score reflects the average of the participants' responses (on a Likert-scale) to a particular statement.

b 1: strongly disagree; 2: disagree; 3: neither agree nor disagree; 4: agree; 5: strongly agree.

statements one and four, with which about $60 \%$ of the participants disagreed. A closer look at these items further showed that these learners were not generally aware of the importance of target language use in improving their communicative skills (statement three) or of the role of input in language learning (statement two, six), on which they remained largely neutral. That statement seven elicited relatively more positive reactions from the participants seems to attest to a possible connection between attitudes towards the EO approach and its comprehensibility.

To sum up the findings of the questionnaire items, the EO approach is not positively received by the young EFL group, who seem to have little sense of the importance of input and speaking English in English classrooms, which may only grow through accumulated learning experience. Some of the youngsters, however, were more ready than others to take advantage of the EO approach, provided that it meets their level of understandability.

Having seen their attitudes, a new variable which merges learners' responses towards the aforementioned statements was created (named "attitudes towards EO"). Cronbach's alpha was .70 for this variable, thus reaching an acceptable level.

The mean and standard deviations for all predictors and criterion variables (English proficiency) are presented in Table 2. The summary of the descriptive statistics for the predictor and criterion variables are as follows:

- As for the English proficiency test, data were normally distributed, indicating that the sample of the present study represents its population in terms of English proficiency.
- Similarly, the participants' scores on the Korean proficiency test were normally distributed, with the mean score being 78.9 (out of 100).

- Regarding vocabulary knowledge, the participants in general knew most of the basic words they are supposed to have acquired prior to the beginning of the sixth grade, but they were not familiar with some vocabulary targeted beyond their current level.

- Based on the mean, the participants were neither enthusiastic nor too skeptical about the EO approach, as stated above.

- The participants reported that they understand approximately $60 \%$ of their teachers' English on average.

The Pearson $r$ was further calculated to establish the correlations of the predictor variables and the English proficiency test scores, which are presented in Table 3.

Table 2 Descriptive statistics for the criterion and predictor variables

\begin{tabular}{lccccc}
\hline Variables & $\boldsymbol{n}$ & Mean & $\begin{array}{c}\text { Standard } \\
\text { deviation }\end{array}$ & Min & Max \\
\hline $\begin{array}{l}\text { Criterion Variable } \\
\quad \text { English proficiency }\end{array}$ & 208 & 30.52 & 10.72 & 5 & 53 \\
$\begin{array}{l}\text { Predictor Variables } \\
\quad \text { Korean proficiency }\end{array}$ & 208 & 78.92 & 12.79 & 42 & 100 \\
$\quad$ Vocabulary knowledge & 208 & 36.39 & 12.63 & 18 & 78 \\
$\quad \begin{array}{l}\text { Attitudes towards English-only } \\
\quad 208\end{array}$ & 2.82 & .64 & 1.14 & 4.43 \\
$\quad \begin{array}{l}\text { The amount of teachers' } \\
\text { English I can understand }\end{array}$ & 208 & 60.61 & 21.62 & 10 & 100 \\
\hline
\end{tabular}


The findings showed that the predictor variables (Korean proficiency, vocabulary knowledge, attitudes towards EO, the amount of teachers' English one can understand) are all significantly related to English proficiency, $p<.01$. All the correlation coefficients are positive, indicating that as the values of the predictor variables increase, the scores of the English proficiency test also increase. The correlation values indicate weak to moderate strengths. The correlation matrix shows that vocabulary knowledge is the most strongly correlated predictor with the English proficiency. However, the predictor variables are not too highly correlated with each other, with the highest correlation coefficient being .39 between the amount of teachers' English one can understand and vocabulary knowledge.

The data were further analyzed using a multiple regression method, which aims to determine a group of predictor variables of interest to us and computes a part of the variance in a criterion variable (English proficiency). It also examines whether each predictor variable contributes significantly to our regression model, while holding constant the effect of other variables. In the analysis, the variables were entered simultaneously into the model without a specified order, as there was no past work providing theoretical considerations based on which a specified regression method could be selected. Following the guidelines of Field (2005), the assumption of independent errors and the assumption of multicollinearity were checked, and it was found that these assumptions were tenable for our dataset (with the Durbin-Watson statistic being 2.12 and VIF values being in the range of 1.13 and 1.37).

The regression analysis showed that the regression model with the four predictors combined has a high correlation with English proficiency $(R=.76)$ and explains $58.3 \%$ of the variance in English proficiency. This value is reduced to $57.5 \%$ when adjusted for the error associated with the predictor variables. The ANOVA results show that the model reaches an $F$ value of 71.07 and a corresponding $p$ value of .001 , indicating that the four predictor variables as a group explain a statistically significant portion of the variance in English proficiency.

A further detailed look at the regression analysis reveals that vocabulary knowledge and Korean proficiency are

Table 3 Correlation between the criterion and predictor variables

\begin{tabular}{|c|c|c|c|c|c|}
\hline Variables & 1 & 2 & 3 & 4 & 5 \\
\hline 1. English proficiency & - & & & & \\
\hline 2. Korean proficiency & $0.50^{* *}$ & - & & & \\
\hline 3. Vocabulary knowledge & $0.69^{* *}$ & $0.38^{* *}$ & - & & \\
\hline 4. Attitudes towards English-only & $0.25^{* *}$ & 0.08 & $0.26^{* *}$ & - & \\
\hline $\begin{array}{l}\text { 5. The amount of teachers' English } \\
\text { I can understand }\end{array}$ & $0.47^{* *}$ & $0.21^{* *}$ & $0.39^{* *}$ & $0.31^{* *}$ & - \\
\hline
\end{tabular}

more strongly related to English proficiency than are the amount of teachers' English one can understand and attitudes towards EO (standardized regression coefficients for vocabulary knowledge, Korean proficiency, and the amount of learners' comprehensibility are $.50, .27$ and .20 , respectively). Indeed, it is found that all of the variables, except for attitudes towards EO, are significant predictors of English proficiency. What this result reveals is that there is no statistically significant relationship between learners' attitudes towards EO and English proficiency, after controlling for the effects of the other predictors. The results from the correlation analysis regarding the positive relation between these two variables (the more positive attitudes one has regarding the EO approach, the higher English proficiency one would have), thus, may be misleading when examining the combined relations among our predictor variables and English proficiency.

\section{Discussions}

The finding that TL learners are not too much in favor of the TL-only approach concurs with the results of some recent studies (e.g., Rolin-Ianziti and Varshney 2008; Yao 2011), but somewhat runs counter to Cameron's (2001) suggestion that young learners “are less inhibited about using the foreign language in lessons" (pp. 204-205). The present study did not explore the issue of teacher code-switching to learners' L1, but one can infer from the finding that only less than $20 \%$ of the learners were embracing the EO teaching approach wholeheartedly that the L1 cannot be completely left out in their learning process. Given that English proficiency was significantly and moderately correlated with the amount of teachers' English one can understand, comprehensibility of EO instruction may be one of the determining factors in terms of their progress in English proficiency; and if EO instruction is likely to hamper this progress at this stage of English learning, we may need to turn to some limited use of learners' L1 (see Swain et al. 2011 for several suggestions), until the learners are more ready to take advantage of such instruction. Their overwhelmingly positive responses to one of the items included in the questionnaire "EO approach would work better for advanced level students" seem to support the above hypothesis. We need to pay more attention to McKay's (2006) note that young learners "need experiences that help them to succeed, to feel good about themselves" (p. 14). If teaching through EO results in the loss of learners' self-esteem or sense of progression, we may need to take a different route towards English language teaching.

The results of the regression analysis showed that the predictors chosen to be part of the regression model explain a significant and large percentage of the score variance of the English proficiency test. The findings disconfirmed one of the hypotheses regarding the EO 
approach, but confirmed the others. The first hypothesis that one's vocabulary knowledge and L1 literacy are strong predictors of TL proficiency was confirmed. In fact, the two variables were found to account for almost half of the variances in English proficiency. That vocabulary knowledge explains a significant part of TL proficiency score variance in the present study concurs with previous studies (e.g., Meara 1996; Nizonkiza 2011; Zareva et al. 2005), despite some differences among the researchers in terms of their research focus. The present study adds more support to the proposition that lexical competence plays a major role in explaining TL proficiency. The other aspect of the findings concerning the first hypothesis was concerned with L1 proficiency, showing that students with higher test scores on the Korean proficiency test also performed well on its English counterpart. This finding can be best interpreted in light of Cummins' Interdependence Hypothesis (1980a, b). The participants in this study are those who surpassed a certain level of L1 proficiency, and thus are subject to the development of TL proficiency via transfer of L1 knowledge. It should be noted that the transfer of knowledge in Cummins' work is more referring to CALP (Cognitive/Academic Language Proficiency) than BICS (Basic Interpersonal Communicative Skills), and it is difficult to estimate the extent to which test items in these proficiency tests reflect the former (or the latter). Examining these items in details, however, it would be safe to say that both types of knowledge are necessary in taking these proficiency tests. In any case, a significant correlation between L1 and English proficiency was found among our sample population.

Our second hypothesis that EFL learners' attitudes towards the EO teaching approach would account for a significant amount of the score variance of the English proficiency test was not confirmed. Although the English proficiency and attitude variables were significantly correlated, albeit weakly, this predictor lost its explanatory power when holding constant the effects of other predictors in the regression analysis. There are two possible explanations for this result. First, the relationship between attitudes towards the EO approach and English proficiency may be contingent on other unspecified variables such as motivation and knowledge of learning strategies (with which to tackle EO instruction). The other explanation is that this variable may only gain its explanatory power for those young EFL learners who are more advanced than the ones involved in the present study or for older learners with more learning strategies and experience.

The third hypothesis that the amount of teachers' English understood would be sensitive to English proficiency, was confirmed. These findings allow one to contend, therefore, that we need to pay more attention to whether our input is being comprehended by our learners, rather than conceiving ways to expose them to an English-only environment; in Bamgbose's (2006) words, "length of instruction in English does not automatically translate into greater competence and more effective education" (p. 651). Apparently, the degree of comprehensibility reported here is a self-evaluated one, and thus may not necessarily be the most accurate measure of learners' level of understanding. However, it still provides an important pedagogical point that might have been previously obscured by a great emphasis on the exclusivity of English instruction.

Lastly, as far as the relationships among vocabulary knowledge, learners' attitudes towards EO and their comprehension level of EO approach are concerned, the findings of the present study imply that building a large vocabulary may be related to having positive attitudes towards EO instruction among learners, and also to enhancing their level of comprehensibility. That is, if one knows a large number of words in TL, it would help him or her grasp TL-based instruction effectively, and consequently have more positive attitudes towards thereof. This finding, although it resonates with our expectations, needs to be read with some caution, partly because these variables were rather weakly correlated (according to the correlation analysis in Table 3), and partly because the study was not originally designed to test this assumption. A more experimental approach would be needed for one to make such a suggestion.

\section{Conclusion}

The present study investigated young EFL learners' English proficiency in relation to several factors which are central to issues of TL teaching. While it does not aim to propose an explanatory model of TL proficiency, the findings of the present study hint that the predictors discussed above may be good candidates in building such a model, at least for the present target population. We have seen that vocabulary knowledge and L1 proficiency have relatively high explanatory power for young EFL learners' English proficiency. These findings provide some pedagogical implication that teachers should not neglect the importance of building vocabulary knowledge at early stages and the level of L1 proficiency in English learning, which have not yet been brought to the table of pedagogical discussion and the educational policy-making process in the EFL context.

The findings regarding learners' attitudes towards the EO teaching approach and their perception of the amount of English instruction they can understand contribute to debates regarding EO policies in teaching as follows: EO may need to be reevaluated in terms of its current status in English teaching, in view of the finding that it is not so favorable to young EFL learners and the attitudes towards such an approach are not highly correlated with English proficiency (i.e., even if a student has a positive attitude 
towards the EO approach, he or she may not necessarily have a high level of English proficiency). The findings of the present study rather suggest that, instead of sticking to an EO diet without empirical evidence showing its superiority over instruction integrating learners' L1, one should investigate various ways to make it more comprehensible. As a way to make English input more comprehensible (and thus promote learners' language acquisition), teachers' limited use of code-switching may be considered, as long as it is used in reference to an evidence-based guideline.

In conclusion, the present study urges an educational policy shift over the English-only approach in the EFL context in light of learners' attitude and its influence on learning, and suggests that it is useful to explore the relationship between some hitherto neglected aspects of TL learning (L1 proficiency, vocabulary knowledge, and learners' perceptions about teachers' language use) and TL proficiency. Furthermore, in view of the growing interest in the spectrum of English as an international language and bilingualism, the English-only approach delivered through one particular English variety (be it US or UK) appears to be neither a learner-favored one, nor a cutting-edge teaching methodology.

\section{Abbreviations}

BALLI: The beliefs about language learning inventory; BICS: Basic interpersonal communicative skills; CA: Contrastive analysis; CALP: Cognitive/ academic language proficiency; EFL: English as a foreign language; ELT: English language teaching; EO: English-only; L1: First language; L2: Second language; TEE: Teaching English in English; TL: Target language; TOSEL: Test of skills in the English Language.

\section{Competing interests}

The author declares that he has no competing interests.

\section{Acknowledgements}

I am thankful to Jonathan Beckett and Bradley Ellis for their review of my first draft. I am also grateful to the teachers and students who participated in the study. Appreciation is extended to the anonymous reviewers for Multilingual Education for their valuable comments and suggestions.

\section{Author details}

Department of English, Korea Military Academy, Seoul, South Korea.

\section{Author's information}

Jang Ho Lee earned his doctorate in Education from the University of Oxford, United Kingdom. His research is focused on teachers' code-switching in English classrooms, the roles of monolingual/bilingual English teachers, and learners' attitudes towards teachers' medium of instruction. He is currently a lecturer of English at Korea Military Academy, Seoul, South Korea.

Received: 10 March 2012 Accepted: 15 June 2012

Published: 15 June 2012

\section{References}

Bamgbose, Ayo. 2006. A recurring decimal: English in language policy and planning. In The Handbook of World Englishes, eds. Braj B. Kachru, Yamuna Kachru, and Cecil L. Nelson, 645-660. Malden, MA: Blackwell

Baumgardner, Robert J. 2006. Teaching world Englishes. In The handbook of World Englishes, eds. Braj B. Kachru, Yamuna Kachru, and Cecil L. Nelson, 661-679. Malden, MA: Blackwell.
Bolton, Kingsley. 2008. English in Asia, Asian Englishes, and the issue of proficiency. English Today 94:3-12.

Bolton, Kingsley, David Graddol, and Christiane Meierkord. 2011. Towards developmental world Englishes. World Englishes 30:459-480.

Burden, Peter. 2004. An examination of attitude change towards the use of Japanese in a university English 'conversation' class. RELC Journal 35(1):21-36.

Cameron, Lynne. 2001. Teaching languages to young learners. Cambridge: Cambridge University Press.

Chavez, Monika. 2003. The diglossic foreign-language classroom: Learners' views on L1 and L2 functions. In The sociolinguistics of foreign-language classrooms: Contributions of the native, the near-native and the non-native speaker, ed. Carl Blyth, 163-208. Boston: Thomson/Heinle.

Choi, Jin-Hwang, Young-Chul Kim, Du-Bon Bae, Wan-Ki Lee, Ui-Gap Lee, and Jae-Geun Lee. 2000. Communicative-oriented lesson models of everyday English and classroom English. Seoul: Korea Institute of Curriculum \& Evaluation.

Cook, Vivian. 1999. Going beyond the native speaker in language teaching. TESOL Quarterly 33(2):185-209.

Cummins, Jim. 1980a. The cross-lingual dimensions of language proficiency: Implications for bilingual education and the optimal age issue. TESOL Quarterly 14(2):175-187.

Cummins, Jim. 1980b. The entry and exit fallacy in bilingual education. In An introductory reader to the writings of Jim Cummins, eds. Colin Baker and Nancy Hornberger, 110-138. Clevedon: Multilingual Matters.

Curriculum Development Council. 2004. English language curriculum guide (Primary 1-6). Hong Kong: Government Logistics Department.

Field, Andy. 2005. Discovering statistics using SPSS. London: SAGE Publications.

Genesee, Fred. 2008. Dual language in the global village. In Pathways to multilingualism: Evolving perspectives on immersion education, eds. Tara Williams Fortune and Diane J. Tedick, 22-45. Clevedon: Multilingual Matters.

Grosjean, François. 1985. The bilingual as a competent but specific speakerhearer. Journal of Multilingual and Multicultural Development 6:467-477.

He, Deyuan, and Lindsay Miller. 2011. English teacher preference: the case of China's non-English-major students. World Englishes 30:428-443.

Henriksen, Brigit. 1999. Three dimensions of vocabulary development. Studies in Second Language Acquisition 21:303-317.

Horwitz, Elaine K. 1999. Cultural and situational influences on foreign language learners' beliefs about language learning: a review of BALLI studies. System 27:557-576.

James, Carl. 1980. Contrastive analysis. New York: Longman.

Jiang, Nan. 2000. Lexical representation and development in a second language. Applied Linguistics 21(1):47-77.

Kachru, Braj B., Yamuna Kachru, and Cecil L. Nelson. 2006. The handbook of World Englishes. Oxford: Blackwell.

Laufer, Batia. 1986. Possible changes in attitude towards vocabulary acquisition research. International Review of Applied Linguistics 24(1):69-75.

Laufer, Batia. 1997. The lexical plight in second language reading. In Second language vocabulary acquisition: A rationale for pedagogy, eds. James Coady and Thomas Huckin, 20-34. Cambridge: Cambridge University Press.

Lee, Jang Ho. 2010. The differential effects of teacher code-switching on the vocabulary acquisition of adult and young EFL learners: A study in the Korean context. Oxford, England: University of Oxford. Unpublished Doctoral Dissertation.

Liu, Dilin, Gil-Soon Ahn, Kyung-Suk Baek, and Nan-Ok Han. 2004. South Korean high school English teachers' code switching: questions and challenges in the drive for maximal use of English in teaching. TESOL Quarterly 38(4):605-638.

Llurda, Enric. 2005. Non-Native language teachers: Perceptions, challenges, and contributions to the profession. Boston, MA: Springer.

Long, Robert. 1997. Investigating and responding to student attitudes and suggestions for course improvement. The Language Teacher Online 21(10). http://jalt-publications.org/old_tlt/files/97/oct/long.html. Accessed 30 October 2011.

Macaro, Ernesto. 2009. Teacher use of codeswitching in the second language classroom: Exploring 'optimal' use. In First language use in second and foreign language learning, eds. Miles Turnbull and Jennifer Dailey-O'Cain, 35-49. Bristol; Buffalo N.Y.: Multilingual Matters.

McKay, Sandra Lee. 2002. Teaching English as an international language. Oxford: Oxford University Press.

McKay, Penny. 2006. Assessing young language learners. Cambridge: Cambridge University Press. 
Meara, Paul. 1996. The dimensions of lexical competence. In Performance and competence in second language acquisition, eds. Gillian Brown, Kirsten Malmkjaer, and John Williams, 35-53. Cambridge: Cambridge University Press.

Meara, Paul, and Barbara Buxton. 1987. An alternative to multiple choice will vocabulary testing. Language Testing 4:142-154

Meara, Paul, and Glyn Jones. 1988. Vocabulary size as a placement indicator. In Linguistics in society, ed. Pamela Grunwell, 80-87. London: CILT.

Medgyes, Peter. 1994. The non-native teacher. London: Macmillan.

Ministry of Education. 2000. Proposals for facilitating English lessons. National Report of the Republic of Korea.

Ministry of Education, Science, and Technology (MOEST). 2009. The National Curriculum for Foreign Languages. Seoul: Ministry of Education, Science and Technology.

Myers-Scotton, Carol. 1993. Social motivations for code-switching: Evidence from Africa. Oxford, UK: Clarendon.

Myers-Scotton, Carol. 2006. Multiple voices: An introduction to bilingualism. Malden, Mass.; Oxford: Blackwell Publishing.

Nation, Paul. 2001. Learning vocabulary in another language. Cambridge: Cambridge University Press.

Nizonkiza, Déogratias. 2011. The relationship between lexical competence, collocational competence, and second language proficiency. English Text Construction 4(1):113-145

Phillipson, Robert. 1992. Linguistic imperialism. Oxford: Oxford University Press. Richards, Jack C. 1976. The role of vocabulary teaching. TESOL Quarterly 10: 77-89.

Rolin-lanziti, Jeanne, and Rachel Varshney. 2008. Students' views regarding the use of the first language: An exploratory study in a tertiary context maximizing target language use. The Canadian Modern Language Review 65 (2):249-273.

Seoul Metropolitan Office of Education. 2010. SMILE project: Strengthening public english education in Seoul. Seoul: Seoul Metropolitan Office of Education

Stockwell, Robert, Jean Donald Bowen, and John Watson Martin. 1965. The grammatical structures of English and Spanish. Chicago, IL: University of Chicago Press.

Swain, Merrill, Andy Kirkpatrick, and Jim Cummins. 2011. How to have a guilt-free life using Cantonese in the English class: A handbook for the English language teacher in Hong Kong. http://www.ied.edu.hk/rcleams/handbook/ handbook.pdf. Accessed 17 April 2012.

Swan, Michael. 1985. A critical look at the communicative approach (2). ELT Journal 39(2):76-87.

TOSEL Organization. 2011. Introductions to TOSEL. http://www.tosel.org Accessed 23 September 2011.

Turnbull, Miles, and Katy Arnett. 2002. Teachers' uses of the target and first language in second and foreign language classrooms. Annual Review of Applied Linguistics 22:204-218.

Yao, Mingfa. 2011. On attitudes to teachers' code-switching in EFL classes. World Journal of English Language 1(1):19-28.

Zareva, Alla, Paula Schwanenflugel, and Yordanka Nikolova. 2005. Relationship between lexical competence and language proficiency: Variable sensitivity. Studies in Second Language Acquisition 27(4):567-595.

Zimmerman, Cheryl B. 1997. Historical trends in second language vocabulary instruction. In Second language vocabulary acquisition: A rationale for pedagogy, eds. James Coady and Thomas Huckin, 5-19. Cambridge: Cambridge University Press.

doi:10.1186/2191-5059-2-5

Cite this article as: Lee: Reassessment of English-only approach in EFL context in view of young learners' attitudes, language proficiency, and vocabulary knowledge. Multilingual Education 2012 2:5. 